Article

\title{
Synthesis and Characterization of Photoluminescence Liquid Crystals Based on Flexible Chain-Bearing Pentafluorinated Bistolanes
}

\author{
Shigeyuki Yamada *(D), Masaya Sato and Tsutomu Konno \\ Faculty of Molecular Chemistry and Engineering, Kyoto Institute of Technology, Matsugasaki, Sakyo-ku, \\ Kyoto 606-8585, Japan; kit.fusso.201803@gmail.com (M.S.); konno@kit.ac.jp (T.K.) \\ * Correspondence: syamada@kit.ac.jp; Tel.: +81-75-724-7517
}

Received: 16 June 2020; Accepted: 9 July 2020; Published: 11 July 2020

\begin{abstract}
The liquid-crystalline (LC) and photophysical properties of molecules are very sensitive to their electronic and molecular aggregate structures. Herein, to shed light on the structure-property relationships of pentafluorinated bistolane-based photoluminescence (PL) liquid crystals (PLLCs) previously reported by our group, we synthesized pentafluorinated bistolanes with variable flexible chains and evaluated their LC and photophysical properties. The incorporation of an oxygen atom (to afford a 2-methoxyethoxy unit) or an oxygen atom and a methyl group (to afford a 1-methoxyprop-2-oxy unit) into the flexible butoxy chain significantly decreased the temperature of the crystalline-to-LC phase transition, and a chiral nematic phase comprising helical molecular aggregates was observed for the chiral 1-methoxyprop-2-oxy group-bearing bistolane. The synthesized bistolanes exhibited strong blue PL in both solution and crystalline phases; the featuring PL characteristics were maintained in the LC phase (produced by the crystalline-to-LC phase transition) except for a slight PL color change. Thus, it was concluded that the PL behavior of pentafluorinated bistolanes can be modulated by the choice of a suitable flexible chain, and the obtained insights are believed to facilitate the application of PLLCs in thermosensing PL materials.
\end{abstract}

Keywords: branched flexible chain; chiral; fluorinated bistolane; light-emitting liquid crystals; linear flexible chain; phase transition; photoluminescence; racemic mixture

\section{Introduction}

The development of novel light-emitting (LE) materials has attracted much attention, as they are widely used to detect cancer cells and protein localization/activity [1-5] and can also find optoelectronic applications, e.g., in lighting or displays [6-10]. Therefore, the exploration of efficient LE molecules for practical applications remains a hot research topic. Although various kinds of LE molecules featuring extended $\pi$-conjugated structures have been reported thus far [11], most of them display luminescence only in the solution phase because of aggregation-caused luminescence quenching in the solid phase [12]. Tang and co-workers [13-16] advocated several light emission phenomena, e.g., crystallization- or aggregation-induced emission; however, the development of LE molecules intensely emitting even in molecular aggregated (e.g., crystalline and liquid-crystalline (LC)) states remains challenging.

Over the past few years, our group has pursued the development of fluorine-containing organic materials and has developed negative-type $\mathrm{LC}$ molecules with the $\mathrm{CF}_{2} \mathrm{CF}_{2}$-containing carbocycles $\mathrm{A}$ and the mesogenic structure $\mathbf{B}$ [17-19]. Moreover, the scope of $\pi$-conjugated photoluminescence (PL) molecules was extended to include a pentafluorinated aromatic scaffold, as exemplified by fluorinated tolanes $\mathbf{C}$ and bistolanes $\mathbf{D}$ (Figure 1a) [20-22]. The investigation of pentafluorinated bistolane-based 
PL molecules revealed that alkoxy-substituted fluorinated bistolanes $\mathbf{E}$ combine both PL and LC characteristics in a single molecule and therefore form light-emitting liquid crystals (PLLCs) [23-26]. Although the PL and LC behaviors of these bistolanes are significantly sensitive to electronic and molecular aggregate structures, the corresponding structure-property relationships remain unclear. Herein, to bridge this knowledge gap, we synthesized PLLCs based on bistolanes 2a (with a linear 2-methoxyethoxy chain) and $\mathbf{2} \mathbf{b}$ (with a branched 1-methoxyprop-2-oxy chain) (Figure $1 \mathbf{b}$ ) as an alternative to the butoxy unit-bearing 1 and characterized their phase transitions and photophysical properties; the variation of side-chain would provide not only lowering phase transition temperature and enhancing PL efficiency in molecular aggregated state.

(a) Previous study
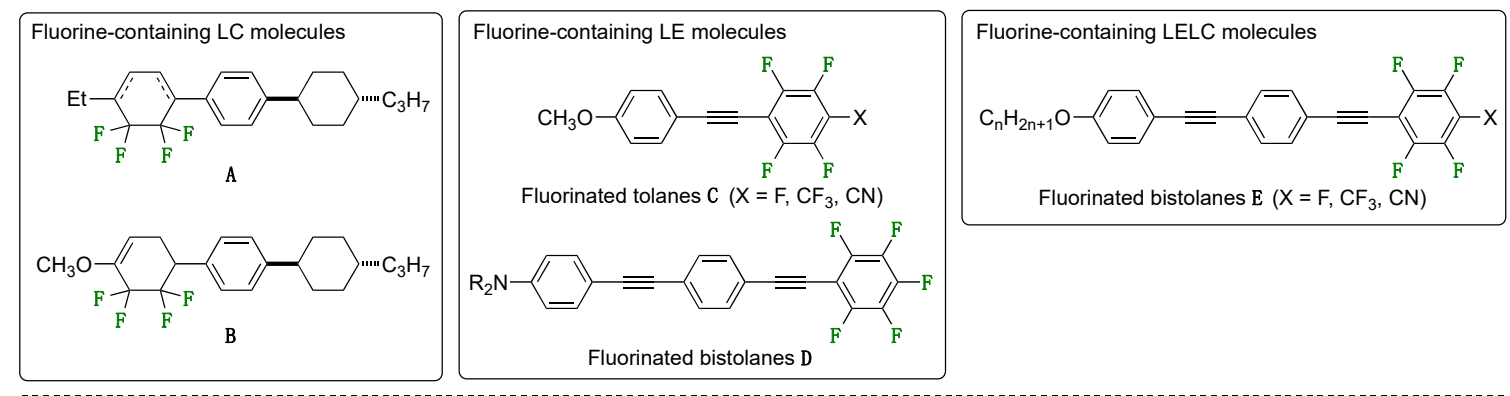

(b) This study
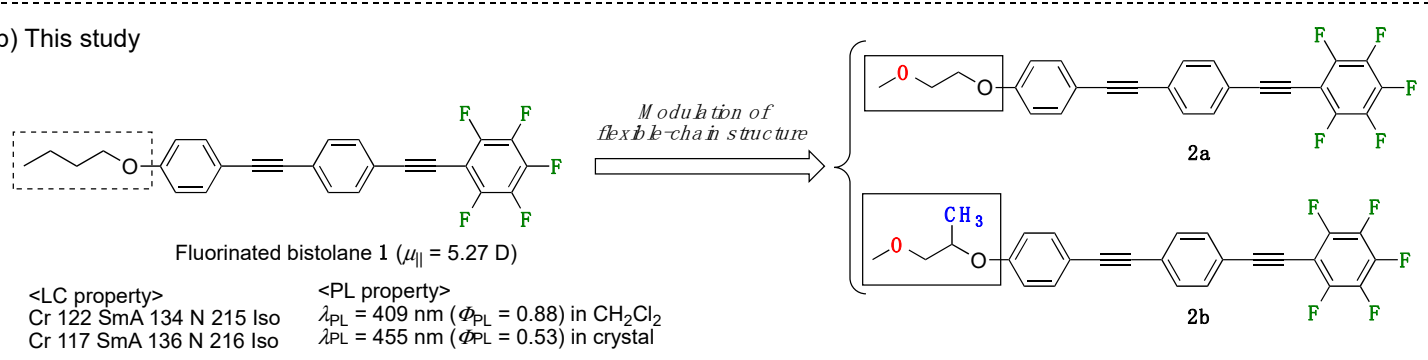

Figure 1. (a) Fluorine-containing organic materials developed in our group and (b) conceptual illustration of the present study.

\section{Materials and Methods}

\subsection{General}

${ }^{1} \mathrm{H}$ and ${ }^{13} \mathrm{C}$ NMR spectra were recorded using an AVANCE III 400 NMR spectrometer (Bruker, Rheinstetten, Germany) $\left({ }^{1} \mathrm{H}: 400 \mathrm{MHz},{ }^{13} \mathrm{C}: 100 \mathrm{MHz}\right)$ in chloroform- $d\left(\mathrm{CDCl}_{3}\right)$ solution, and chemical shifts were reported in parts per million (ppm) and referenced to the residual proton signal of the NMR solvent. ${ }^{19} \mathrm{~F}$ NMR $(376 \mathrm{MHz})$ spectra were acquired in $\mathrm{CDCl}_{3}$ solution with $\mathrm{CFCl}_{3}\left(\delta_{\mathrm{F}}=0\right.$ $\mathrm{ppm}$ ) as an internal standard using the same instrument. Infrared (IR) spectra were recorded on a FT/IR-4100 type A spectrometer (JASCO, Tokyo, Japan) using the KBr pellet method. High-resolution mass spectrometry (HRMS) analysis was performed on a JMS-700MS instrument (JEOL, Tokyo, Japan) using fast atom bombardment $(\mathrm{FAB})$ as an ionization method. All reactions were performed using dried glassware and a magnetic stir bar. All chemicals were of reagent grade and were purified in the usual manner prior to use when necessary. Column chromatography was conducted using silica gel (FUJIFILM Wako Pure Chemical Corporation, Wako-gel@60N, 38-100 $\mu \mathrm{m}$; Osaka, Japan), while thin layer chromatography (TLC) was performed on silica gel TLC plates (Merck, Silica gel $60 \mathrm{~F}_{254}$; New Jersey, NJ, USA).

\subsection{Materials}

Pentafluorinated bistolanes 2a (with a linear 2-methoxyethoxy unit) and $\mathbf{2 b}$ (with a branched 1-methoxyprop-2-oxy flexible chain) were prepared from the corresponding 4-substituted 
phenylacetylene derivatives $\mathbf{3} \mathbf{a}$ and $\mathbf{3} \mathbf{b}$ accessible from commercially available 2-bromoethanol and methyl lactate, respectively (Scheme 1 ). The synthesis of $R-\mathbf{2} \mathbf{b}$ starting from $R-\mathbf{3} \mathbf{b}$ is described below as a representative example.

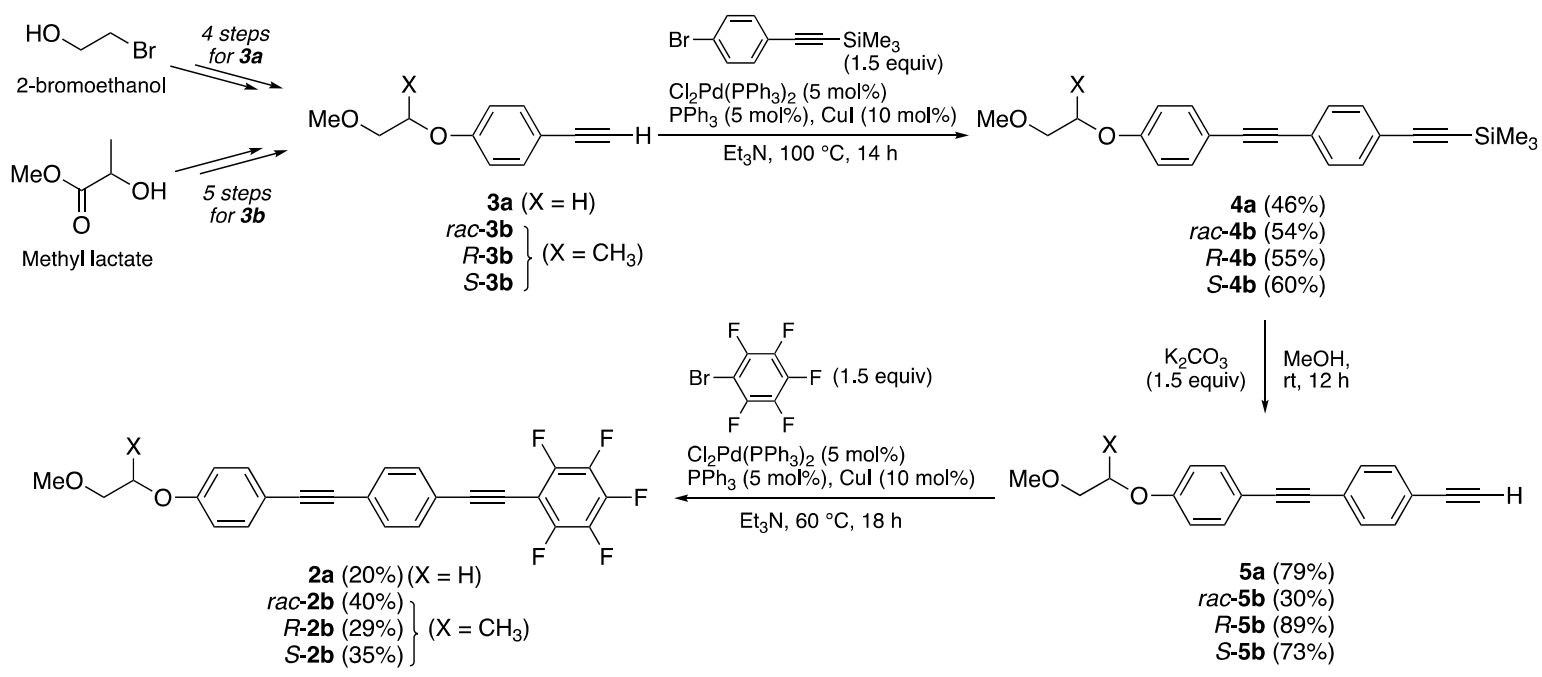

Scheme 1. Syntheses of pentafluorinated bistolanes $\mathbf{2 a}$ and $\mathbf{2 b}$.

\subsection{Typical Synthesis of $R-\mathbf{4 b}$}

A 50-mL two-necked round-bottomed flask with a Teflon ${ }^{\circledR}$-coated stir bar and a reflux condenser was charged with 1-bromo-4-[2-(trimethylsilyl)ethyn-1-yl]benzene (3.92 g, $15.5 \mathrm{mmol}), \mathrm{Cl}_{2} \mathrm{Pd}_{\left(\mathrm{PPh}_{3}\right)_{2}}$ ( $0.33 \mathrm{~g}, 0.70 \mathrm{mmol}), \mathrm{PPh}_{3}(0.13 \mathrm{~g}, 0.70 \mathrm{mmol}), \mathrm{CuI}(0.24 \mathrm{~g}, 1.6 \mathrm{mmol})$, and $\mathrm{Et}_{3} \mathrm{~N}(45 \mathrm{~mL})$, and the obtained mixture was supplemented with a solution of (R)-4-(1-methoxyprop-2-yloxy)phenylacetylene $(3 \mathbf{b} ; 2.08$ $\mathrm{g}, 11 \mathrm{mmol})$ in $\mathrm{Et}_{3} \mathrm{~N}(20 \mathrm{~mL})$ at $25^{\circ} \mathrm{C}$. After 14-h stirring at $100^{\circ} \mathrm{C}$, the precipitate was separated by atmospheric filtration, and the filtrate was poured into saturated aqueous $\mathrm{NH}_{4} \mathrm{Cl}(20 \mathrm{~mL})$. The mixture was extracted with EtOAc $(3 \times 20 \mathrm{~mL})$, and the organic layer was washed with brine $(20 \mathrm{~mL})$, dried over anhydrous $\mathrm{Na}_{2} \mathrm{SO}_{4}$, filtered, and concentrated in vacuo using a rotary evaporator. The obtained residue was purified by silica gel column chromatography using $n$-hexane:EtOAc $(15: 1, \mathrm{v} / \mathrm{v})$ as an eluent to obtain the desired product $(R-4 \mathrm{~b} ; 2.17 \mathrm{~g}, 6.0 \mathrm{mmol})$ as a pale-green solid in $55 \%$ yield.

[2-[4-[2-(4-(2-Methoxyethoxy)phenyl)ethyn-1-yl]phenyl]ethyn-1-yl]trimethylsilane (4a)

Yield: $46 \%$ (pale-green solid); m.p.: $124.6-126.0{ }^{\circ} \mathrm{C} ;{ }^{1} \mathrm{H}$ NMR $\left(\mathrm{CDCl}_{3}\right): \delta 0.26(\mathrm{~s}, 9 \mathrm{H}), 3.45(\mathrm{~s}, 3 \mathrm{H})$, $3.75(\mathrm{t}, J=4.7 \mathrm{~Hz}, 2 \mathrm{H}), 4.13(\mathrm{t}, J=4.5 \mathrm{~Hz}, 2 \mathrm{H}), 6.90(\mathrm{~d}, J=8.8 \mathrm{~Hz}, 2 \mathrm{H}), 7.43(\mathrm{~s}, 4 \mathrm{H}), 7.45(\mathrm{~d}, J=8.8 \mathrm{~Hz}$, $2 \mathrm{H}) ;{ }^{13} \mathrm{C} \mathrm{NMR}\left(\mathrm{CDCl}_{3}\right): \delta 0.04,59.4,67.4,71.0,88.0,91.5,96.1,104.8,114.8,115.4,122.6,123.8,131.3$, 132.0, 133.2, 158.2; IR (KBr): v 2958, 2877, 2348, 2214, 2190, 1596, 1453, 1252, $1147 \mathrm{~cm}^{-1}$; HRMS (FAB) calcd for $[\mathrm{M}]^{+} \mathrm{C}_{22} \mathrm{H}_{24} \mathrm{O}_{2} \mathrm{Si}$ : 348.1548 , found 348.1549 .

[2-[4-[2-(4-(1-Methoxyprop-2-oxy)phenyl)ethyn-1-yl]phenyl]ethyn-1-yl]trimethylsilane (4b)

Yield: $55 \%$ for $R$-configuration, $54 \%$ for $S$-configuration, and $60 \%$ for racemic mixture (pale-green solid); m.p.: $60.9-61.4{ }^{\circ} \mathrm{C}$ for $R$-configuration; ${ }^{1} \mathrm{H}$ NMR $\left(\mathrm{CDCl}_{3}\right): \delta 0.27(\mathrm{~s}, 9 \mathrm{H}), 1.31(\mathrm{~d}, J=6.2 \mathrm{~Hz}, 3 \mathrm{H})$, $3.40(\mathrm{~s}, 3 \mathrm{H}), 3.45-3.59(\mathrm{~m}, 2 \mathrm{H}), 4.52-4.56(\mathrm{~m}, 1 \mathrm{H}), 6.90(\mathrm{~d}, J=8.8 \mathrm{~Hz}, 2 \mathrm{H}), 7.44(\mathrm{~s}, 4 \mathrm{H}), 7.46(\mathrm{~d}, J=8.8 \mathrm{~Hz}$, 2H); ${ }^{13} \mathrm{C} \mathrm{NMR}\left(\mathrm{CDCl}_{3}\right): \delta 0.0,16.8,59.4,73.0,75.7,87.8,91.6,96.0,104.8,115.2,115.9,122.5,123.8,131.2$, 131.9, 133.2, 158.2; IR (KBr): $v$ 2967, 2880, 2358, 2212, 2155, 1594, 1519, 1260, $1140 \mathrm{~cm}^{-1}$; HRMS (FAB) calcd for $[\mathrm{M}]^{+} \mathrm{C}_{23} \mathrm{H}_{26} \mathrm{O}_{2} \mathrm{Si}: 362.1702$, found 362.1693 . 


\subsection{Typical Synthesis of $R-\mathbf{5 b}$}

A two-necked round-bottomed flask with a Teflon ${ }^{\circledR}$-coated stir bar was charged with freshly prepared $R-4 \mathbf{b}(2.17 \mathrm{~g}, 6.0 \mathrm{mmol})$ and $\mathrm{K}_{2} \mathrm{CO}_{3}(0.12 \mathrm{~g}$, $9.0 \mathrm{mmol})$ in methanol $(20 \mathrm{~mL})$, and the mixture was stirred at $25^{\circ} \mathrm{C}$ for $12 \mathrm{~h}$. The precipitate was separated by atmospheric filtration, and the filtrate was poured into saturated aqueous $\mathrm{NH}_{4} \mathrm{Cl}(20 \mathrm{~mL})$. The mixture was extracted with EtOAc $(3 \times 40$ $\mathrm{mL})$, and the organic layer was washed with brine $(20 \mathrm{~mL})$, dried over anhydrous $\mathrm{Na}_{2} \mathrm{SO}_{4}$, filtered, and concentrated in vacuo using a rotary evaporator. The obtained residue was purified by silica gel column chromatography using $n$-hexane:EtOAc $(15: 1, \mathrm{v} / \mathrm{v})$ as an eluent to obtain the desired product $(R-5 \mathbf{b} ; 1.6 \mathrm{~g}, 5.3 \mathrm{mmol})$ as a pale-green solid in $89 \%$ yield.

4-[2-[4-(2-Methoxyethoxy)phenyl]ethyn-1-yl]phenylacetylene (5a)

Yield: 79\% (pale-green solid); m.p.: $110.7-111.6{ }^{\circ} \mathrm{C} ;{ }^{1} \mathrm{H}$ NMR $\left(\mathrm{CDCl}_{3}\right): \delta 3.17(\mathrm{~s}, 1 \mathrm{H}), 3.46(\mathrm{~s}, 3 \mathrm{H})$, $3.75(\mathrm{t}, J=4.6 \mathrm{~Hz}, 2 \mathrm{H}), 4.13(\mathrm{t}, J=4.6 \mathrm{~Hz}, 2 \mathrm{H}), 6.90(\mathrm{~d}, J=8.8 \mathrm{~Hz}, 2 \mathrm{H}), 7.45(\mathrm{~s}, 4 \mathrm{H}), 7.46(\mathrm{~d}, J=8.8 \mathrm{~Hz}$, 2H); ${ }^{13} \mathrm{C} \mathrm{NMR}\left(\mathrm{CDCl}_{3}\right): \delta 59.4,67.4,71.0,78.9,83.5,87.8,91.6,114.8,115.4,121.6,125.2,131.4,132.2$, 133.2, 159.2; IR (KBr): $v$ 3246, 2991, 2884, 2374, 2213, 1596, 1507, 1453, 1252, $1147 \mathrm{~cm}^{-1}$; HRMS (FAB) calcd for $[\mathrm{M}]^{+} \mathrm{C}_{19} \mathrm{H}_{16} \mathrm{O}_{2}: 276.1150$, found 276.1145 .

4-[2-(4-(1-Methoxyprop-2-oxy)phenyl)ethyn-1-yl]phenylacetylene (5b)

Yield: $89 \%$ for $R$-configuration, $73 \%$ for $S$-configuration, $30 \%$ for racemic mixture (pale-green solid); m.p.: $54.3-55.1{ }^{\circ} \mathrm{C}$ for $R$-configuration; ${ }^{1} \mathrm{H}$ NMR $\left(\mathrm{CDCl}_{3}\right): \delta 1.31(\mathrm{~d}, J=6.2 \mathrm{~Hz}, 3 \mathrm{H}), 3.19(\mathrm{~s}, 1 \mathrm{H})$, $3.40(\mathrm{~s}, 3 \mathrm{H}), 3.45-3.59(\mathrm{~m}, 2 \mathrm{H}), 4.52-4.59(\mathrm{~m}, 1 \mathrm{H}), 6.91(\mathrm{~d}, J=8.8 \mathrm{~Hz}, 2 \mathrm{H}), 7.46(\mathrm{~s}, 4 \mathrm{H}), 7.47(\mathrm{~d}, J=8.8 \mathrm{~Hz}$, 2H); ${ }^{13} \mathrm{C} \mathrm{NMR}\left(\mathrm{CDCl}_{3}\right): \delta 16.7,59.3,73.0,75.7,78.9,83.4,87.7,91.6,115.1,115.9,121.5,124.2,131.3$, 132.0, 133.2, 158.2; IR (KBr): $v$ 3230, 2983, 2835, 2330, 2214, 1594, 1511, 1256, $1092 \mathrm{~cm}^{-1}$; HRMS (FAB) calcd for $[\mathrm{M}]^{+} \mathrm{C}_{20} \mathrm{H}_{18} \mathrm{O}_{2}$ : 290.1307, found 290.1300.

\subsection{Typical Synthesis of $R-\mathbf{2} \mathbf{b}$}

A two-necked round-bottomed flask with a Teflon ${ }^{\circledR}$-coated stir bar and a reflux condenser was charged with $R-5 \mathbf{b}$ (1.6 g, $5.3 \mathrm{mmol}), \mathrm{Cl}_{2} \mathrm{Pd}\left(\mathrm{PPh}_{3}\right)_{2}(0.19 \mathrm{~g}, 0.30 \mathrm{mmol}), \mathrm{PPh}_{3}(0.07 \mathrm{~g}, 0.3 \mathrm{mmol})$, and $\mathrm{Et}_{3} \mathrm{~N}(20 \mathrm{~mL})$. The obtained homogenous mixture was supplemented with $\mathrm{CuI}(0.10 \mathrm{~g}, 0.50 \mathrm{mmol})$ and a solution of bromopentafluorobenzene $(0.8 \mathrm{~mL}, 7.6 \mathrm{mmol})$ in $\mathrm{Et}_{3} \mathrm{~N}(10 \mathrm{~mL})$. After stirring for 18 $\mathrm{h}$ at $100{ }^{\circ} \mathrm{C}$, the produced precipitate was separated by atmospheric filtration, and the filtrate was poured into saturated aqueous $\mathrm{NH}_{4} \mathrm{Cl}(40 \mathrm{~mL})$. The mixture was extracted with EtOAc $(3 \times 40 \mathrm{~mL})$, and the organic layer was washed with brine $(20 \mathrm{~mL})$, dried over anhydrous $\mathrm{Na}_{2} \mathrm{SO}_{4}$, filtered, and concentrated in vacuo using a rotary evaporator. The obtained residue was purified by silica gel column chromatography using $n$-hexane:EtOAc $(15: 1, \mathrm{v} / \mathrm{v})$ as an eluent followed by reprecipitation from $\mathrm{CH}_{2} \mathrm{Cl}_{2}: \mathrm{MeOH}(1: 1, \mathrm{v} / \mathrm{v})$ to obtain the desired product $(R-2 \mathbf{b}, 0.70 \mathrm{~g}, 1.5 \mathrm{mmol})$ as a white crystalline powder in $29 \%$ yield.

1-[2-(4-Methoxyethoxyphenyl)ethyn-1-yl]-4-[2-(2,3,4,5,6-pentafluorophenyl)ethyn-1-yl]benzene (2a)

Yield: $20 \%$ (white crystalline powder); m.p.: $133{ }^{\circ} \mathrm{C}$ (determined by differential scanning calorimetry (DSC; second heating process)); ${ }^{1} \mathrm{H} \mathrm{NMR}\left(\mathrm{CDCl}_{3}\right): \delta 3.46(\mathrm{~s}, 3 \mathrm{H}), 3.78(\mathrm{t}, J=4.6 \mathrm{~Hz}, 2 \mathrm{H})$, $4.15(\mathrm{t}, J=4.7 \mathrm{~Hz}, 2 \mathrm{H}), 6.91(\mathrm{~d}, J=8.8 \mathrm{~Hz}, 2 \mathrm{H}), 7.47(\mathrm{~d}, J=8.8 \mathrm{~Hz}, 2 \mathrm{H}), 7.50-7.55(\mathrm{~m}, 4 \mathrm{H}) ;{ }^{13} \mathrm{C} \mathrm{NMR}$ $\left(\mathrm{CDCl}_{3}\right): \delta 59.4,67.5,71.0,74.7,87.8,92.3,100.3,101.4,114.9,115.3,120.9,125.2,131.6,131.9,133.3$, 136.7-139.1 (m, aromatic carbons attached to fluorine), 140.4-142.9 (m, aromatic carbons attached to fluorine), $146.1-148.5$ ( $\mathrm{m}$, aromatic carbons attached to fluorine), $159.3 ;{ }^{19} \mathrm{~F} \mathrm{NMR}\left(\mathrm{CDCl}_{3}\right): \delta-162.11$ to $-161.98(\mathrm{~m}, 2 \mathrm{~F}),-152.78(\mathrm{t}, J=22.0 \mathrm{~Hz}, 1 \mathrm{~F}),-136.28$ to $-136.21(\mathrm{~m}, 2 \mathrm{~F}) ; \mathrm{IR}(\mathrm{KBr})$ : v 2990, 2887, 2338, 2203, 1523, 1297, 1262, $1130 \mathrm{~cm}^{-1}$; HRMS (FAB) calcd for $[\mathrm{M}]^{+} \mathrm{C}_{25} \mathrm{H}_{15} \mathrm{~F}_{5} \mathrm{O}_{2}: 442.0992$, found 442.0995 . 
1-[2-(4-(1-Methoxyprop-2-oxy)phenyl)ethyn-1-yl]-4-[2-(2,3,4,5,6-pentafluorophenyl)ethyn-1-yl]benzene $(2 b)$

Yield: $29 \%$ for $R$-configuration, 35\% for $S$-configuration, and $40 \%$ for racemic mixture; m.p.: $102{ }^{\circ} \mathrm{C}$ for $R$ - and $S-\mathbf{2} \mathbf{b}, 97{ }^{\circ} \mathrm{C}$ for rac-2b (determined by DSC (second heating process)); ${ }^{1} \mathrm{H}$ NMR $\left(\mathrm{CDCl}_{3}\right): \delta 1.33(\mathrm{~d}, J=6.3 \mathrm{~Hz}, 3 \mathrm{H}), 3.42(\mathrm{~s}, 3 \mathrm{H}), 3.48-3.62(\mathrm{~m}, 2 \mathrm{H}), 4.55-4.62(\mathrm{~m}, 1 \mathrm{H}), 6.91(\mathrm{~d}, J=8.8 \mathrm{~Hz}$, $2 \mathrm{H}), 7.46(\mathrm{~d}, J=8.8 \mathrm{~Hz}, 2 \mathrm{H}), 7.50-7.56(\mathrm{~m}, 4 \mathrm{H}) ;{ }^{13} \mathrm{C} \mathrm{NMR}\left(\mathrm{CDCl}_{3}\right): \delta 16.8,59.5,73.2,74.7,75.9,87.7,92.4$, 100.4-101.2 (m), 101.4, 115.1, 116.1, 120.9, 125.2, 131.6, 131.9, 133.3, 136.6-139.1 (m, aromatic carbons attached to fluorine), 140.4-142.9 (m, aromatic carbons attached to fluorine), 145.9-148.4 (m, aromatic carbons attached to fluorine), 158.5; IR (KBr): $v$ 3009, 2990, 2857, 2367, 2212, 1595, 1526, 1497, 1243, $1112 \mathrm{~cm}^{-1}$; HRMS (FAB) calcd for $[\mathrm{M}]^{+} \mathrm{C}_{26} \mathrm{H}_{17} \mathrm{~F}_{5} \mathrm{O}_{2}: 456.1149$, found 456.1153 .

\subsection{Computations}

All computations were performed using density functional theory (DFT) and the Gaussian 16 (Revision B.01) software package [27]. Geometry optimizations were executed using the M06-2X hybrid functional $[28,29]$ and the $6-31+G(d)$ basis set with the implicit solvation model (conductor-like polarizable continuum model (CPCM) [30-32]) for $\mathrm{CH}_{2} \mathrm{Cl}_{2}$. The vertical excitation energies and dipole moments of optimized structures were calculated using the time-dependent DFT (TD-DFT) method at the same level of theory.

\subsection{Phase Transition Behavior}

Phase transition behaviors were observed by polarizing optical microscopy (POM) using a BX53 microscope (Olympus, Tokyo, Japan) equipped with a cooling and heating stage (Linkam Scientific Instruments, 10002L; Surrey, UK). Thermodynamic characterization was performed by DSC (Shimadzu DSC-60 Plus; Kyoto, Japan) at heating and cooling rates of $5.0^{\circ} \mathrm{C} \mathrm{min}^{-1}$ under $\mathrm{N}_{2}$.

\subsection{Photophysical Behavior}

UV-vis absorption spectra were recorded on a V-500 absorption spectrometer (JASCO, Tokyo, Japan). Samples for absorption measurements were prepared by dissolving crystalline $\mathbf{2 a}$ or $\mathbf{2} \mathbf{b}$ in a common organic solvent to a concentration of $1.0 \times 10^{-5} \mathrm{~mol} \mathrm{~L}^{-1}$ and transferring the solution to a quartz cuvette with an optical path length of $1 \mathrm{~cm}$. Steady-state photoluminescence (PL) spectra and PL quantum yields (PLQYs) in solution and crystalline states were obtained using a FP-6000 fluorescence spectrometer (JASCO, Tokyo, Japan) and an absolute PLQY measurement system (Hamamatsu Photonics KK., C11347-01, Hamamatsu, Japan). PL measurements were performed for $1.0 \times 10^{-6} \mathrm{~mol} \mathrm{~L}^{-1}$ solutions using quartz cuvettes with an optical path length of $1 \mathrm{~cm}$. The excitation wavelength $\left(\lambda_{\mathrm{ex}}\right)$ corresponded to the maximum absorption wavelength. For excitation and PL measurements, crystalline powder samples were placed between two quartz glass plates. PL samples containing LC phases were prepared by flash-freezing in a liquid $\mathrm{N}_{2}$ bath after the thermal phase transition and were placed between two quartz glass plates. For measurements of PLQY in the crystalline state, samples were placed above a quartz Petri dish and characterized using a calibrated integrating sphere.

\section{Results and Discussion}

\subsection{Theoretical Molecular Design and Synthesis}

The validity of our molecular design for $\mathbf{2} \mathbf{a}$ and $\mathbf{2} \mathbf{b}$ was ascertained by the theoretical assessment of these compounds using M06-2X/6-31+G(d)-level DFT calculations and the CPCM for $\mathrm{CH}_{2} \mathrm{Cl}_{2}$. In addition, previously reported compound $\mathbf{1}$ bearing a simple butoxy chain was characterized as a reference. Figure 2 shows the optimized geometries as well as highest occupied molecular orbital (HOMO) and lowest unoccupied molecular orbital (LUMO) distributions for $\mathbf{1}, \mathbf{2} \mathbf{a}$, and S-2b, while Table 1 summarizes the calculated HOMO and LUMO energy levels, molecular dipole moments 
$\left(\mu_{\|}\right)$along the longitudinal molecular axis, vertical electronic transitions obtained by time-dependent (TD)-DFT calculations, transition energies, and oscillator strengths (Figures S15-S17 and Tables S1-S6).

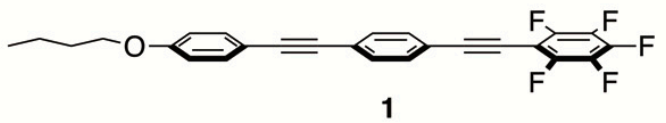

1

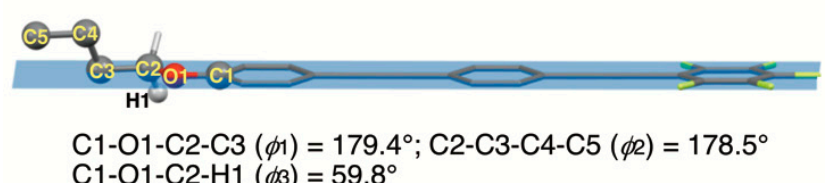

$\mathrm{C} 1-\mathrm{O} 1-\mathrm{C} 2-\mathrm{H} 1(\phi 3)=59.8^{\circ}$

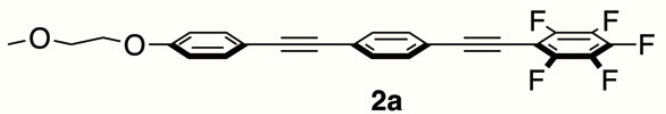

$2 a$

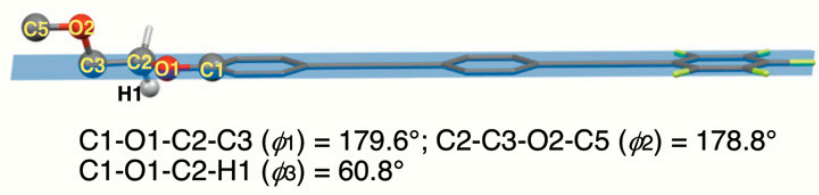

C1-O1-C2-C3 $(\phi 1)=179.6^{\circ}$
C1-O1-C2-H1 $(\phi \beta)=60.8^{\circ}$
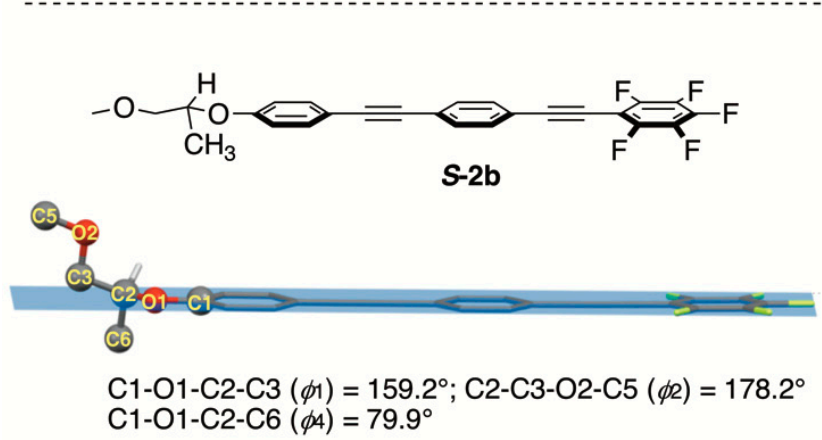

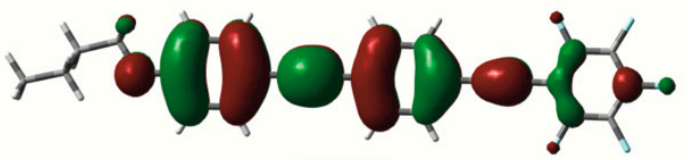

HOMO

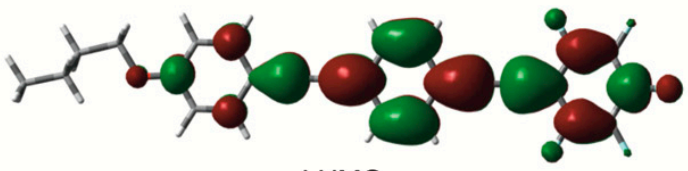

LUMO

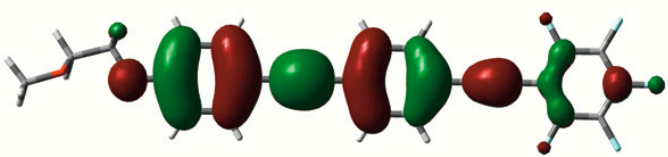

HOMO

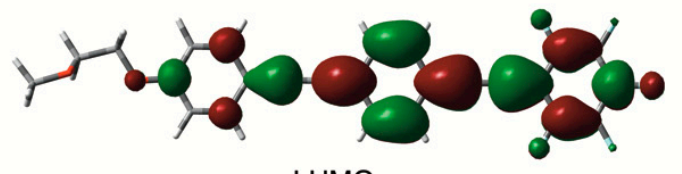

LUMO

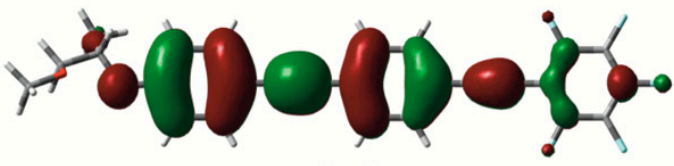

HOMO

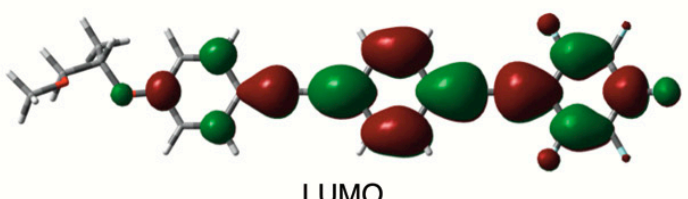

LUMO

Figure 2. Optimized molecular geometries as well as frontier molecular orbital distributions for 1, 2a, and $S-2 \mathbf{b}$ calculated by density functional theory at the M06-2X/6-31+G(d) level.

Table 1. Results of quantum chemical calculations. ${ }^{1 .}$

\begin{tabular}{ccccc}
\hline Molecule & $\boldsymbol{\mu}_{\|} \mathbf{( D )}^{\mathbf{2}}$ & $\begin{array}{c}\text { HOMO/LUMO }^{3} \\
\mathbf{( e V )}\end{array}$ & $\begin{array}{c}\text { Theoretical Transition } \\
\text { Energy }(\mathbf{n m})^{\mathbf{4}}\end{array}$ & $f^{\mathbf{5}}$ \\
\hline $\mathbf{1}$ & 5.28 & $-7.05 /-1.59$ & $335 \mathrm{~nm}$ & 2.298 \\
$\mathbf{2 a}$ & 6.21 & $-7.06 /-1.59$ & $334 \mathrm{~nm}$ & 2.294 \\
$S-\mathbf{2 b}$ & 6.73 & $-7.04 /-1.59$ & $335 \mathrm{~nm}$ & 2.305 \\
\hline
\end{tabular}

${ }_{1}$ Computed at the M06-2X/6-31+G(d) level of theory using the conductor-like polarizable continuum model (CPCM) for $\mathrm{CH}_{2} \mathrm{Cl}_{2} .{ }^{2}$ Dipole moment along the longitudinal molecular axis. ${ }^{3}$ Highest occupied/lowest unoccupied molecular orbitals. ${ }^{4}$ Obtained by time-dependent density functional theory calculations using the CPCM for $\mathrm{CH}_{2} \mathrm{Cl}_{2} \cdot{ }^{5}$ Oscillator strength.

$\mu_{\|}$, which helps one to quantitatively understand the electron density distribution, was calculated as $5.28,6.21$, and $6.73 \mathrm{D}$ for $\mathbf{1}, \mathbf{2} \mathbf{a}$, and $S-\mathbf{2} \mathbf{b}$, respectively, i.e., the induction effect of the electronegative oxygen atom in the flexible units of $\mathbf{2} \mathbf{a}$ and $\mathbf{2 b}$ increased $\mu_{\|}$. Accordingly, the change of the flexible unit from a simple alkoxy chain to the 2-methoxyethoxy fragment allowed one to control the electron density distribution on the pentafluorinated bistolane moiety and thus enabled the easy tuning of phase transition and photophysical properties. Regarding the molecular geometries of $\mathbf{1}$ and $\mathbf{2 a}$, the oxygen 
atom in the flexible unit did not induce any change in the molecular structure, whereas in the case of $\mathbf{2 b}$, the methyl substituent significantly altered the molecular geometry, effectively inducing a large deviation of the flexible chain from the plane of the bistolane scaffold. These deviations were quantified by comparison of C1-O1-C2-C3 $\left(\phi_{1}\right), \mathrm{C} 2-\mathrm{C} 3-\mathrm{C} 4(\mathrm{O} 2)-\mathrm{C} 5\left(\phi_{2}\right), \mathrm{C} 1-\mathrm{O} 1-\mathrm{C} 2-\mathrm{H} 1\left(\phi_{3}\right)$, and C1-O1-C2-C6 $\left(\phi_{4}\right)$ dihedral angles, and $\left(\phi_{1}, \phi_{2}, \phi_{3}\right)$ values of $\left(179.4^{\circ}, 178.5^{\circ}, 59.8^{\circ}\right)$ for 1 and $\left(179.6^{\circ}, 178.8^{\circ}, 60.8^{\circ}\right)$ for $\mathbf{2 a}$, and $\left(\phi_{1}, \phi_{2}, \phi_{4}\right)$ values of $\left(159.2^{\circ}, 178.2^{\circ}, 79.9^{\circ}\right)$ for $S-2 \mathbf{b}$ were obtained. These data suggested that the incorporation of a methyl substituent into the flexible unit (i.e., branching) significantly altered molecular geometry and could therefore affect aggregation behavior. As a whole, the transition from $\mathbf{1}$ (carrying a simple alkoxy unit) to $\mathbf{2 a}$ (carrying a linear 2-methoxyethoxy unit) and $\mathbf{2} \mathbf{b}$ (bearing a branched 1-methoxyprop-2-oxy unit) was used to elucidate the effect of molecular structure on the phase transition behaviors and photophysical properties of PLLC molecules.

2-Methoxyethoxy-substituted 2a was prepared from 2-bromoethanol, while 1-methoxyprop-2-oxysubstituted $\mathbf{2 b}$ was prepared from methyl lactate with various configurations (i.e., racemic mixture or $R$-/S-configuration; Scheme 1). The 2-methoxyethoxy-substituted phenylacetylene $\mathbf{3} \mathbf{b}$, easily accessible from 2-bromoethanol in four steps, was coupled with 1-bromo-4-(2-trimethylsilylethyn-1-yl)benzene in the presence of catalytic amounts of $\mathrm{Cl}_{2} \mathrm{Pd}\left(\mathrm{PPh}_{3}\right)_{2}, \mathrm{PPh}_{3}$, and $\mathrm{CuI}$ in $\mathrm{Et}_{3} \mathrm{~N}$ at $100{ }^{\circ} \mathrm{C}$ for $14 \mathrm{~h}$ to afford $4 \mathrm{a}$ in $46 \%$ isolated yield. Removal of the trimethylsilyl group in $4 \mathbf{a}$ with $\mathrm{K}_{2} \mathrm{CO}_{3}$ in $\mathrm{MeOH}$ at $25{ }^{\circ} \mathrm{C}$ for $12 \mathrm{~h}$ smoothly furnished the corresponding terminal acetylene $5 \mathrm{a}$ in $79 \%$ isolated yield. Further Sonogashira cross-coupling of $5 \mathbf{a}$ with bromopentafluorobenzene promoted by $\mathrm{Cl}_{2} \mathrm{Pd}\left(\mathrm{PPh}_{3}\right)_{2}$, $\mathrm{PPh}_{3}$, and CuI produced the desired pentafluorinated bistolane $\mathbf{2 a}$, which was purified by column chromatography followed by recrystallization. Other analogues bearing a 1-methoxyprop-2-yloxy flexible chain, namely rac-2 $\mathbf{b}, R-\mathbf{2} \mathbf{b}$, and $S-\mathbf{2} \mathbf{b}$, were obtained using a similar three-step protocol and purified as in the case of $\mathbf{2} \mathbf{a}$. As a result, $\mathbf{2} \mathbf{a}$ and $\mathbf{2} \mathbf{b}$ were found to be sufficiently pure for phase transition and photophysical behavior characterization (Figures S1-S14).

\subsection{Phase Transition Behavior}

The phase transition behaviors of freshly prepared $\mathbf{2} \mathbf{a}, r a c-\mathbf{2} \mathbf{b}, R-\mathbf{2} \mathbf{b}$, and $S-\mathbf{2} \mathbf{b}$ were probed by DSC and POM. Figure 3 shows the corresponding DSC thermograms recorded during the second heating and cooling cycles, with the obtained phase transition sequences and enthalpies summarized in Table 2 and Tables S7-S10.

Table 2. Phase transition behaviors of $\mathbf{2} \mathbf{a}, r a c-\mathbf{2} \mathbf{b}, R-\mathbf{2} \mathbf{b}$, and $S-\mathbf{2} \mathbf{b} .{ }^{1}$.

\begin{tabular}{|c|c|c|}
\hline \multicolumn{2}{|c|}{ Molecule } & \multirow{2}{*}{$\begin{array}{c}\left.\left.\text { Phase Transition Sequence (Enthalpy [kJ mol }{ }^{-\mathbf{1}}\right]\right)^{\mathbf{2}} \\
\text { Cr } 134 \text { (27.3) N } 212(0.58) \text { Iso }\end{array}$} \\
\hline $2 a$ & Heating & \\
\hline & Cooling & Cr $127(-26.2)$ N $212(-0.49)$ Iso \\
\hline \multirow[t]{2}{*}{ rac-2b } & Heating & Cr1 61 (1.21) Cr2 $82(-5.64)$ Cr3 97 (28.9) N 129 (0.23) Iso \\
\hline & Cooling & Cr1 $54(-0.79)$ Cr2 $79(-4.40)$ Cr3 $87(-17.5)$ N $129(-0.29)$ Iso \\
\hline \multirow[t]{2}{*}{$R-2 b$} & Heating & Cr $102(117.1) \mathrm{N}^{*} 130(0.88)$ Iso \\
\hline & Cooling & Cr $85(-111.9) N^{*} 130(-0.81)$ Iso \\
\hline \multirow[t]{2}{*}{$S-2 b$} & Heating & Cr $102(32.9) \mathrm{N}^{*} 130(0.35)$ Iso \\
\hline & Cooling & Cr $85(-31.7) \mathrm{N}^{*} 130(-0.26)$ Iso \\
\hline
\end{tabular}

${ }^{1}$ Determined for the second heating and cooling processes. ${ }^{2}$ Determined by differential scanning calorimetry and polarizing optical microscopy. Abbreviations: Cr: crystal, N: nematic, $\mathrm{N}^{*}$ : chiral nematic, Iso: isotropic phases.

Upon heating to $134^{\circ} \mathrm{C}$, the crystalline (Cr) phase of $\mathbf{2 a}$ changed to an LC phase with a fluidic bright-view optical texture. Optical imaging of the LC phase afforded a four-brush Schlieren image typical of the nematic $(\mathrm{N})$ phase; thus, $2 \mathrm{a}$ formed the nematic LC phase in the second heating step. Further heating of the $\mathrm{N}$-phase of $\mathbf{2 a}$ to $212{ }^{\circ} \mathrm{C}$ resulted in a new phase transition that was accompanied by a POM texture change from a Schlieren image to a fluidic dark-view field. The latter image was assigned to an isotropic (Iso) phase with no directional and positional orders. During the cooling step, two phase transitions were observed at $212{ }^{\circ} \mathrm{C}(\mathrm{Iso} \rightarrow \mathrm{N})$ and $127^{\circ} \mathrm{C}(\mathrm{N} \rightarrow \mathrm{Cr})$. Compared to that of 1 
(Figure $1 \mathrm{~b}$ ), the $\mathrm{Cr} \rightarrow \mathrm{N}$ transition temperature of $2 \mathrm{a}$ was higher by approximately $10^{\circ} \mathrm{C}$, and hence, the incorporation of oxygen into the flexible unit was concluded to enhance the stability of the Cr-phase, possibly by allowing for intermolecular hydrogen bonding.
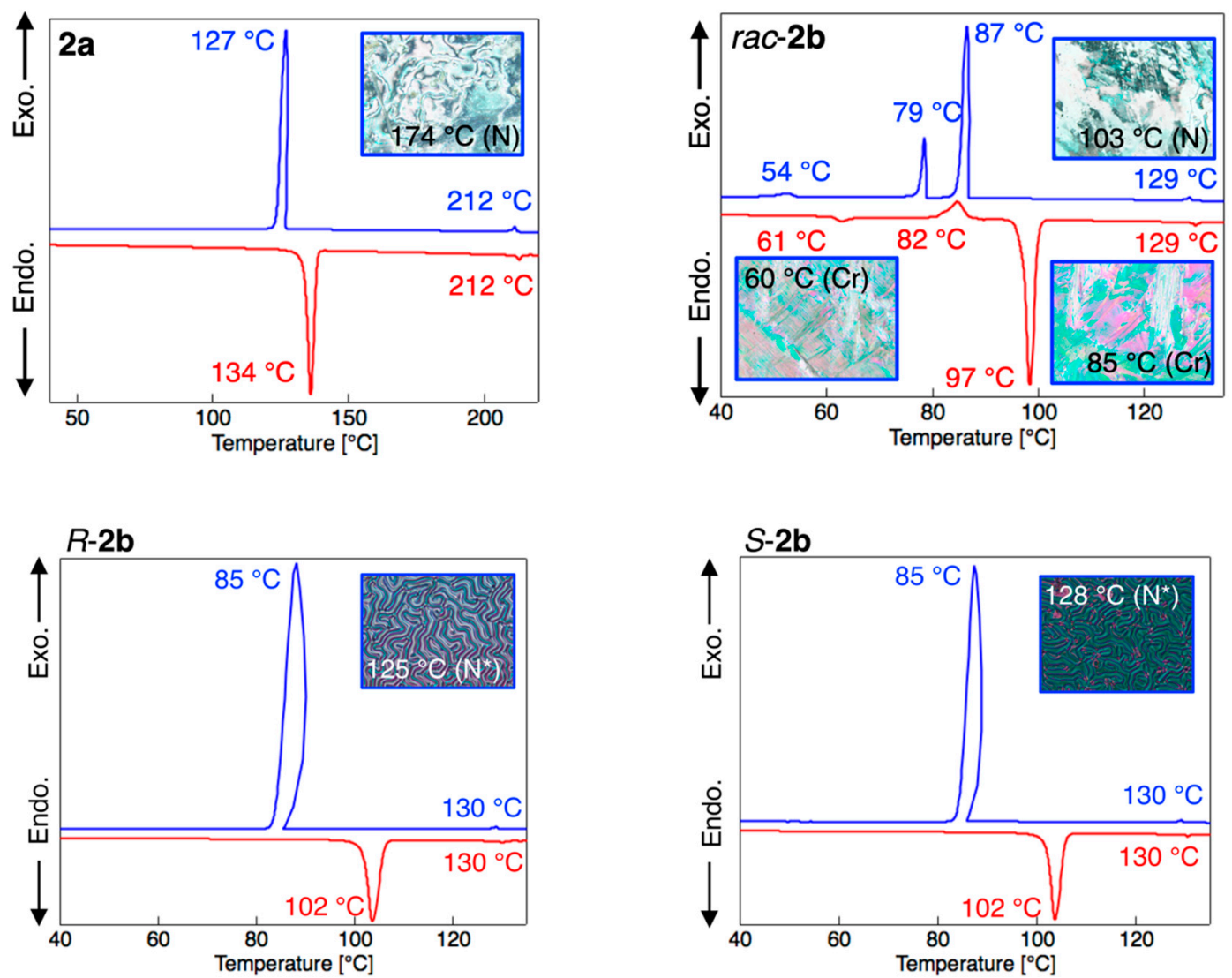

Figure 3. Differential scanning calorimetry thermograms of $\mathbf{2} \mathbf{a}$, rac-2 $\mathbf{b}, R-\mathbf{2} \mathbf{b}$, and $S-\mathbf{2} \mathbf{b}$ recorded during the second heating and cooling cycles. Microphotographs indicate optical textures of the selected crystalline and liquid-crystalline phases observed by polarizing optical microscopy. Cr: crystal, N: nematic, $\mathrm{N}^{*}$ : chiral nematic, Iso: isotropic phases.

In the case of rac-2b, the nematic LC phase was also detected by POM and DSC, with $\mathrm{Cr} \rightarrow \mathrm{N}$ and $\mathrm{N} \rightarrow$ Iso transitions observed at 97 and $129^{\circ} \mathrm{C}$, respectively, i.e., at temperatures much lower (by approximately $40^{\circ} \mathrm{C}$ for $\mathrm{Cr} \rightarrow \mathrm{N}$ and by $83^{\circ} \mathrm{C}$ for $\mathrm{N} \rightarrow$ Iso) than those of 2 a. This behavior was not unexpected, as the methyl substituent of $\mathbf{2 b}$ readily destructed the ordered crystalline lattice and directionally ordered $\mathrm{N}$ phases. The chiral species, i.e., $R-\mathbf{2} \mathbf{b}$ and $S-\mathbf{2} \mathbf{b}$, exhibited $\mathrm{Cr} \rightarrow$ mesophase (at $102{ }^{\circ} \mathrm{C}$ ) and mesophase $\rightarrow$ Iso (at $130^{\circ} \mathrm{C}$ ) phase transitions during the second heating process. Careful POM observation of the mesophase revealed a fingerprint texture typical of the chiral nematic $\left(\mathrm{N}^{*}\right)$ phase and thus suggested the formation of helical molecular aggregates in the chiral LC phases of $R-\mathbf{2} \mathbf{b}$ and $S-\mathbf{2} \mathbf{b}$. Compared to those of rac- $\mathbf{2} \mathbf{b}$, the phase transitions of chiral $R-\mathbf{2} \mathbf{b}$ and $S-\mathbf{2} \mathbf{b}\left(C r \rightarrow \mathrm{N}^{*}\right.$ and $\mathrm{N}^{*} \rightarrow$ Iso) occurred at slightly higher temperatures, which is a generally reported phenomenon [33].

Thus, the change from a simple alkoxy chain to a linear or a branched 2-methoxyethoxy-type flexible unit strongly influenced phase transition behavior, while the incorporation of an oxygen atom and a methyl substituent significantly reduced the temperature of both $\mathrm{Cr} \rightleftarrows \mathrm{LC}$ and $\mathrm{LC} \rightleftarrows$ Iso transitions. In addition, a chiral flexible unit was concluded to be essential for the generation of helical structures induced by the formation of a chiral LC (i.e., $\mathrm{N}^{*}$ ) phase [34]. 


\subsection{Photophysical Behavior}

\subsubsection{Photophysical Behavior in Solution}

To gain more insights into flexible-chain structures, we focused on their effect on photophysical behavior. First, the absorption and PL properties of $\mathbf{2} \mathbf{a}, r a c-\mathbf{2} \mathbf{b}, R-\mathbf{2} \mathbf{b}$, and $S-\mathbf{2} \mathbf{b}$ were investigated in dilute $\mathrm{CH}_{2} \mathrm{Cl}_{2}$ solutions $\left(1.0 \times 10^{-5} \mathrm{~mol} \mathrm{~L}^{-1}\right.$ for absorption and $1.0 \times 10^{-6} \mathrm{~mol} \mathrm{~L}^{-1}$ for PL measurements). Figure 4a and Figure S22 shows the absorption and PL spectra of $\mathrm{CH}_{2} \mathrm{Cl}_{2}$ solutions as well as photographs of these solutions under UV irradiation $\left(\lambda_{\mathrm{ex}}=365 \mathrm{~nm}\right)$, with the collected photophysical data summarized in Table 3. In addition, Figure $4 \mathrm{~b}$ shows the positions of the investigated samples on the PL color diagram defined by the Comission Internationale de l'Eclairage (CIE).

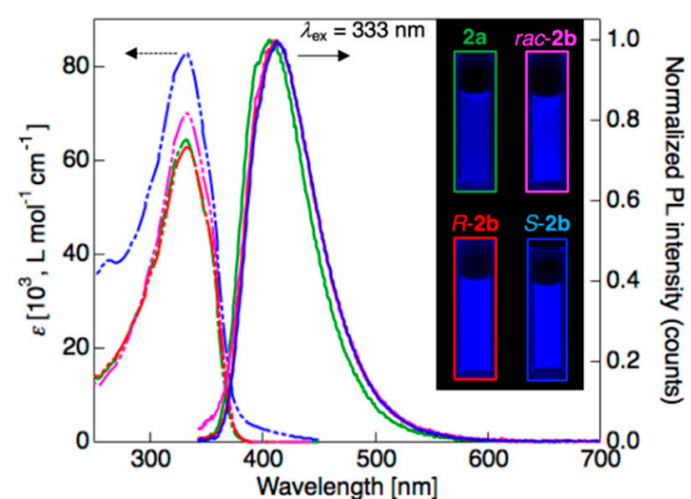

(a)

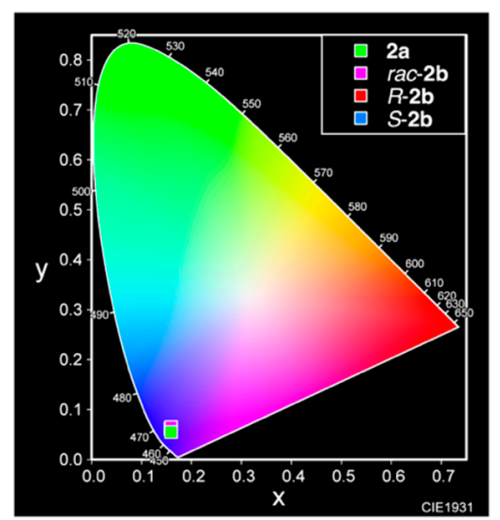

(b)

Figure 4. (a) UV-vis absorption and photoluminescence spectra $\left(\lambda_{\mathrm{ex}}=333 \mathrm{~nm}\right)$ of $\mathbf{2 a}, \mathrm{rac}-\mathbf{2} \mathbf{b}, R-\mathbf{2} \mathbf{b}$, and $S-2 \mathbf{b}$ in $\mathrm{CH}_{2} \mathrm{Cl}_{2}$ solutions and photographs of these solutions under UV irradiation $\left(\lambda_{\mathrm{ex}}=365 \mathrm{~nm}\right)$. (b) Positions of the samples in (a) on the Comission Internationale de l'Eclairage (CIE) color diagram.

Table 3. Photophysical properties of $\mathbf{2} \mathbf{a}, r a c-\mathbf{2} \mathbf{b}, R-\mathbf{2} \mathbf{b}$, and $S-\mathbf{2} \mathbf{b}$ in solution.

\begin{tabular}{|c|c|c|c|c|}
\hline Molecule & Solvent $(\varepsilon)^{1}$ & 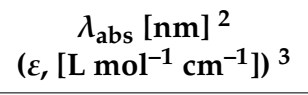 & 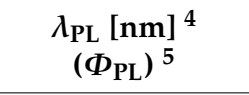 & $\begin{array}{c}\text { CIE Coordinate } \\
(x, y)\end{array}$ \\
\hline $2 a$ & $\mathrm{CH}_{2} \mathrm{Cl}_{2}(8.93)$ & $332(64300)$ & $406(0.91)$ & $(0.16,0.19)$ \\
\hline$r a c-2 b$ & $\mathrm{CH}_{2} \mathrm{Cl}_{2}(8.93)$ & $333(70000)$ & $412(0.70)$ & $(0.15,0.11)$ \\
\hline$R-2 b$ & $\mathrm{CH}_{2} \mathrm{Cl}_{2}(8.93)$ & $333(62900)$ & $412(0.88)$ & $(0.16,0.10)$ \\
\hline \multirow{6}{*}{$S-2 b$} & $\mathrm{CH}_{2} \mathrm{Cl}_{2}(8.93)$ & $332(82700)$ & $412(0.99)$ & $(0.16,0.09)$ \\
\hline & Toluene (2.38) & $335(58100)$ & 381,397 sh $(0.79)$ & $(0.16,0.04)$ \\
\hline & $\mathrm{CHCl}_{3}(4.81)$ & $333(57300)$ & 393,404 sh (0.93) & $(0.16,0.04)$ \\
\hline & THF (7.58) & $333(53500)$ & $416(0.98)$ & $(0.16,0.06)$ \\
\hline & $\mathrm{MeCN}(35.9)$ & $329(56200)$ & $434(0.92)$ & $(0.16,0.12)$ \\
\hline & DMF (36.7) & 333 (41700) & $443(0.71)$ & $(0.17,0.15)$ \\
\hline
\end{tabular}

Figure 4a shows that the spectra of $\mathbf{2 a}, r a c-\mathbf{2} \mathbf{b}, R-\mathbf{2} \mathbf{b}$, and $S-\mathbf{2} \mathbf{b}$ featured a single absorption band with a maximum $\left(\lambda_{\mathrm{abs}}\right)$ at around $333 \mathrm{~nm}$ and exhibited identical shapes, which indicated that in dilute solution, these species possessed the same (i.e., flexible chain-independent) electronic structure. The observed maximum absorption wavelengths $(333 \mathrm{~nm})$ were almost in accord with the theoretical vertical transition energies ( $334 \mathrm{~nm}$ or $335 \mathrm{~nm}$ ) predicted by TD-DFT calculations (Table 1), and the electronic transitions observed in absorption spectra were therefore identified as HOMO $\rightarrow$ LUMO ones. Analysis of the HOMO and LUMO of $\mathbf{2} \mathbf{a}$ and $\mathbf{S - 2} \mathbf{b}$ showed that the HOMO lobes were largely localized on the electron-rich aromatic ring attached to the flexible unit, while LUMO lobes were 
localized on the electron-deficient pentafluorobenzene ring. The above distributions and the relatively large longitudinal molecular dipole moment suggested that the present $\mathrm{HOMO} \rightarrow \mathrm{LUMO}$ electronic transition was of the intramolecular charge transfer (ICT) type.

Irradiation of dilute sample solutions in $\mathrm{CH}_{2} \mathrm{Cl}_{2}$ at $\lambda_{\mathrm{abs}}$ resulted in strong PL with maxima $\left(\lambda_{\mathrm{PL}}\right)$ at $406 \mathrm{~nm}(\mathbf{2 a})$ and $412 \mathrm{~nm}(\mathbf{2 b})$, with PL efficiency $\left(\Phi_{\mathrm{PL}}\right)$ reaching 0.90 . According to the CIE color diagram, the $\mathrm{CH}_{2} \mathrm{Cl}_{2}$ solutions of $\mathbf{2 a}$ and $\mathbf{2} \mathbf{b}$ showed deep blue PL that was independent of the flexible chain structure, although slight differences were observed between samples $((x, y)=(0.16,0.19)$ for $\mathbf{2 a}$, $(0.15,0.11)$ for $r a c-2 \mathbf{b},(0.16,0.10)$ for $R-\mathbf{2} \mathbf{b}$, and $(0.16,0.09)$ for $S-2 \mathbf{b})$. Considering the almost identical PL behavior of the above species in $\mathrm{CH}_{2} \mathrm{Cl}_{2}$ solution, their strong deep blue PL was concluded to originate from the same process of radiative exciton deactivation (i.e., ICT).

To gain further insights into electronic transitions from the ground state to excited states, we investigated the effect of solvent on the photophysical behavior of $\mathbf{S - 2} \mathbf{b}$. Figure $5 \mathbf{a}$ and Figure S23 shows the results of absorption and PL measurements for common organic solvents, namely toluene, chloroform $\left(\mathrm{CHCl}_{3}\right)$, tetrahydrofuran (THF), acetonitrile $(\mathrm{MeCN})$, and $\mathrm{N}, \mathrm{N}$-dimethylformamide (DMF), with the corresponding CIE color diagram shown in Figure $5 b$.

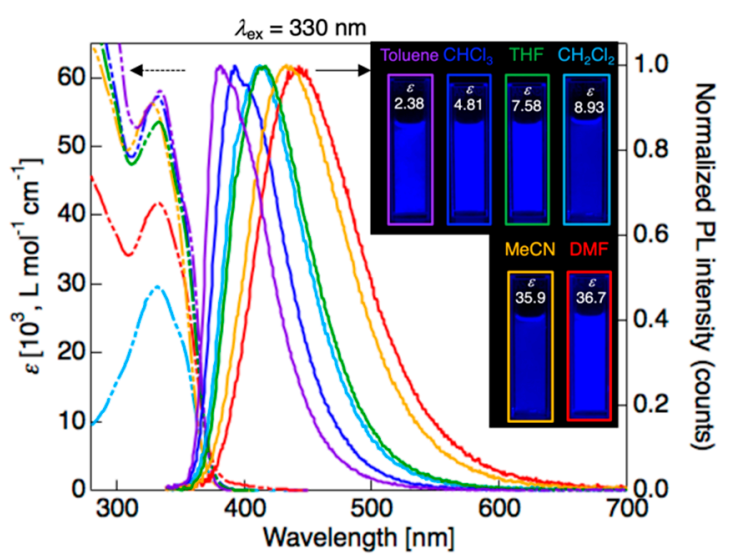

(a)

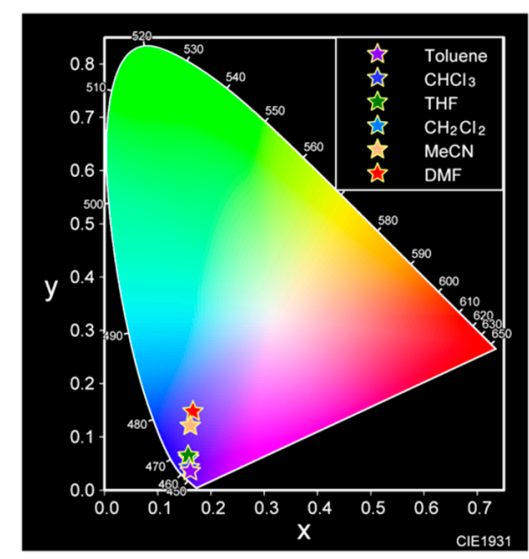

(b)

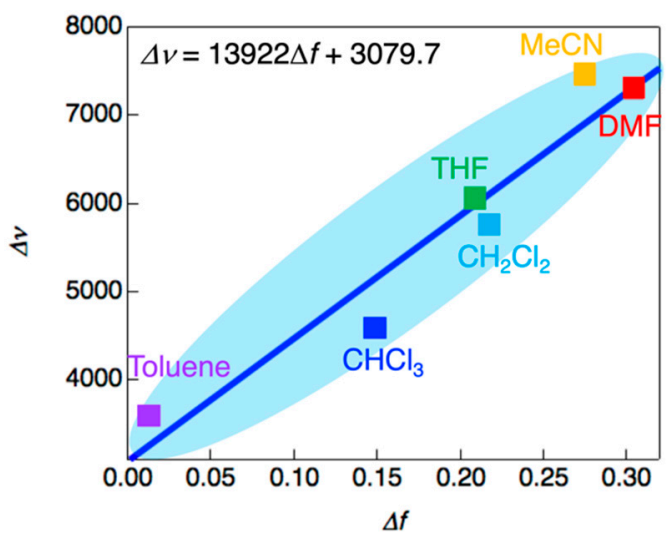

(c)

Figure 5. (a) UV-vis absorption and photoluminescence (PL) spectra $\left(\lambda_{\mathrm{ex}}=330 \mathrm{~nm}\right)$ of $S-\mathbf{2 b}$ in various organic solvents recorded at concentrations of $1.0 \times 10^{-5} \mathrm{~mol} \mathrm{~L}^{-1}$ and $1.0 \times 10^{-6} \mathrm{~mol} \mathrm{~L}^{-1}$, respectively. Inset: PL colors under UV irradiation $\left(\lambda_{\mathrm{ex}}=365 \mathrm{~nm}\right)$. (b) CIE color diagram with positions of PL observed in various solvents upon excitation at $330 \mathrm{~nm}$. (c) Lippert-Mataga plot.

The values of $\lambda_{\mathrm{abs}}$ obtained by UV-vis absorption measurements (330-333 nm) were almost independent of solvent polarity, in contrast to $\lambda_{\mathrm{PL}}(381-443 \mathrm{~nm})$. The relationship between solvent polarity and photophysical behavior was quantitatively evaluated with the help of a Lippert-Mataga 
plot (Figure 5c, Table S11) [35-37], which shows the dependence of Stokes' shift $(\Delta v)$ on orientation polarizability $(\Delta f)$ calculated from the solvent dielectric constant $(\varepsilon)$ and refractive index $(n)$ (Equation (1)):

$$
\Delta v=\left[2\left(\mu_{\mathrm{e}}-\mu_{\mathrm{g}}\right)^{2} / h c a^{3}\right] \Delta f+\text { constant. }
$$

Here, $\mu_{\mathrm{e}}$ and $\mu_{\mathrm{g}}$ are the dipole moments of the ground and excited states, respectively, $a$ is the Onsager cavity radius, $h$ is Planck's constant, and $c$ is the speed of light in vacuum. Figure $5 c$ shows that the relationship between orientation polarizability and Stokes' shift could be expressed as $\Delta v=13922 \Delta f$ +3079.7 , which allowed $\mu_{\mathrm{e}}-\mu_{\mathrm{g}}$ to be calculated as $17.1 \mathrm{D}$ and thus indicated that the molecular dipole moment of the excited state is much larger than that of the ground state. Therefore, it could be safely concluded that the electronic transition from the ground to excited states corresponds to ICT process.

\subsubsection{Photophysical Behavior in Molecular Aggregated Phases}

Subsequently, we focused on the PL behavior of $\mathbf{2 a}$ and $\mathbf{2 b}$ in the Cr-phase, with the corresponding PL spectra and CIE color diagram presented in Figure 6 and Figure S24. Table 4 lists photophysical data measured for the $\mathrm{Cr}$-phase at $25^{\circ} \mathrm{C}$ and for the LC phase.

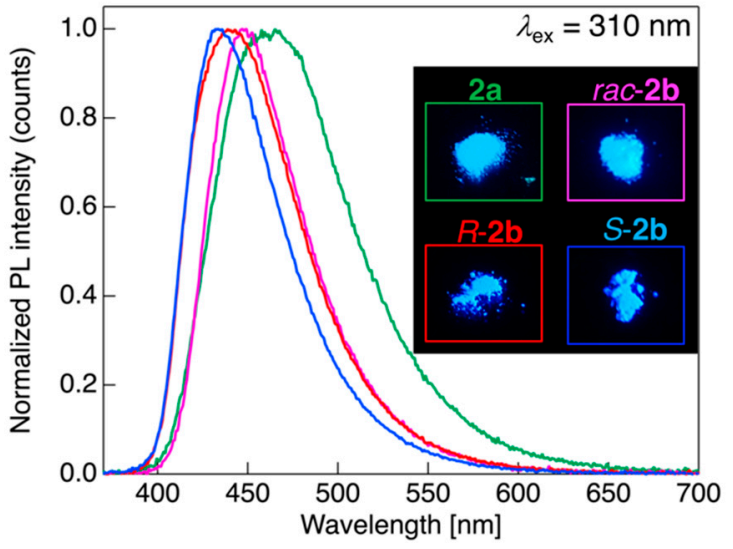

(a)

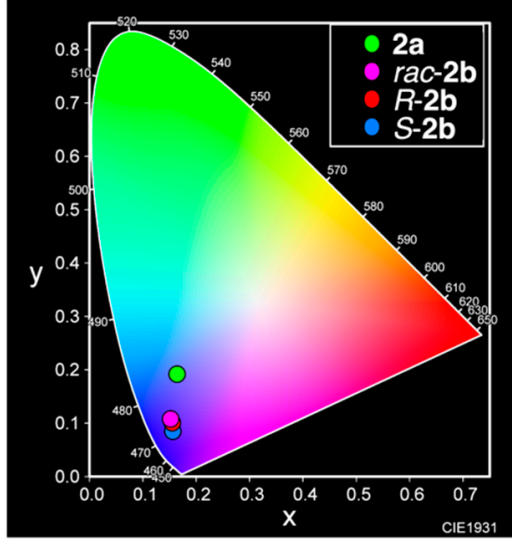

(b)

Figure 6. (a) Photoluminescence (PL) spectra of $\mathbf{2} \mathbf{a}, r a c-\mathbf{2} \mathbf{b}, R-\mathbf{2} \mathbf{b}$, and $S-\mathbf{2} \mathbf{b}$ in the Cr-phase. (b) CIE color diagram showing the PL colors of samples in (a).

Table 4. Photophysical data of $\mathbf{2} \mathbf{a}, r a c-\mathbf{2} \mathbf{b}, R-\mathbf{2} \mathbf{b}$, and $S-\mathbf{2} \mathbf{b}$ measured for crystalline and liquid-crystalline phases.

\begin{tabular}{cccc}
\hline Molecule & Phase $^{\mathbf{1}}$ & $\lambda_{\mathbf{P L}}[\mathbf{n m}]^{\mathbf{2}}\left(\boldsymbol{\Phi}_{\mathbf{P L}}\right)^{3}$ & CIE Coordinate $(\boldsymbol{x}, \boldsymbol{y})$ \\
\hline $\mathbf{2 a}$ & $\mathrm{Cr}$ & $465(0.39)$ & $(0.16,0.19)$ \\
& $\mathrm{N}$ & $412 \mathrm{sh}, 442(0.17)$ & $(0.16,0.12)$ \\
rac-2b & $\mathrm{Cr}$ & $449(0.70)$ & $(0.15,0.11)$ \\
& $\mathrm{N}$ & $434(0.58)$ & $(0.16,0.10)$ \\
$\boldsymbol{R}-\mathbf{2 b}$ & $\mathrm{Cr}$ & $439(0.68)$ & $(0.16,0.10)$ \\
& $\mathrm{N}^{*}$ & $436(0.41)$ & $(0.16,0.10)$ \\
S-2b & $\mathrm{Cr}$ & $432(0.74)$ & $(0.16,0.08)$ \\
& $\mathrm{N}^{*}$ & $435(0.40)$ & $(0.16,0.10)$
\end{tabular}

${ }^{1}$ Phase identified by polarizing optical microscopy. ${ }^{2}$ Excitation wavelength $=310 \mathrm{~nm} .{ }^{3}$ Obtained using an absolute photoluminescence quantum yield measurement system with an integrating sphere. Abbreviations: Cr: crystal, N: nematic, $\mathrm{N}^{*}$ : chiral nematic, Iso: isotropic phases. sh: shoulder.

As shown in Figure 6a, 2a showed blue PL $((x, y)=(0.16,0.19))$ with a single band $\left(\lambda_{\mathrm{PL}} \approx 465 \mathrm{~nm}\right)$ red-shifted by approximately $60 \mathrm{~nm}$ relative to that in $\mathrm{CH}_{2} \mathrm{Cl}_{2}$ solution. For $r a c-2 \mathbf{b}, R-\mathbf{2} \mathbf{b}$, and $S-\mathbf{2 b}$, deep blue PL with a single band at $432-449 \mathrm{~nm}$ was observed at $25^{\circ} \mathrm{C}$, and the PL bands were also 
red-shifted (by 20-37 nm) relative to those in $\mathrm{CH}_{2} \mathrm{Cl}_{2}$ solution. The red shift of $\lambda_{\mathrm{PL}}$ observed for the $\mathrm{Cr}$-phase is a common phenomenon that is typically ascribed to non-radiative exciton deactivation via intermolecular interactions. Much to our delight, the $\Phi_{\mathrm{PL}}$ of $\mathrm{Cr}$ phases lied in the range of 0.39-0.74. As mentioned above, the PL of molecules with extended $\pi$-conjugation is rapidly quenched in the solid state, possibly because of energy transfer through $\pi / \pi$ stacking. In the present cases, the flexible unit was believed to facilitate the expansion of the interfacial $\pi \cdots \pi$ distance to avoid tight $\pi / \pi$ stacking, although the accurate structures of aggregates in the Cr-phase remain unclear [38].

The LC and PL behavior of the synthesized bistolanes inspired us to probe their PLLC properties. To ascertain the applicability of these bistolanes to PLLC molecules, we investigated the PL behavior of LC phases. For these measurements, samples were prepared by flash-freezing through dipping into a liquid $\mathrm{N}_{2}$ bath after the thermal phase transition to the LC phase, which allowed us to probe PL behavior at $25^{\circ} \mathrm{C}$ while preserving the molecular aggregates in the LC phase. Figure 7 and Figure S25 shows the PL spectra of powder samples containing molecular aggregates in $\mathrm{Cr}$ and LC phases, with related photophysical data listed in Table 4.

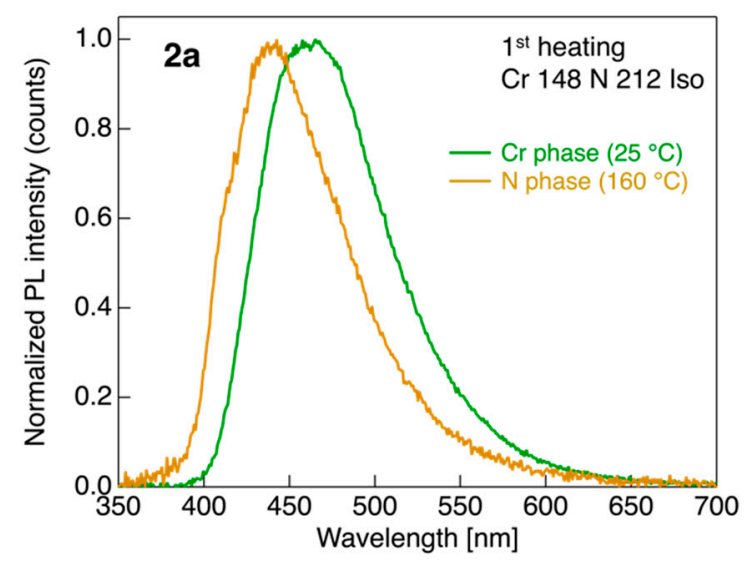

(a)

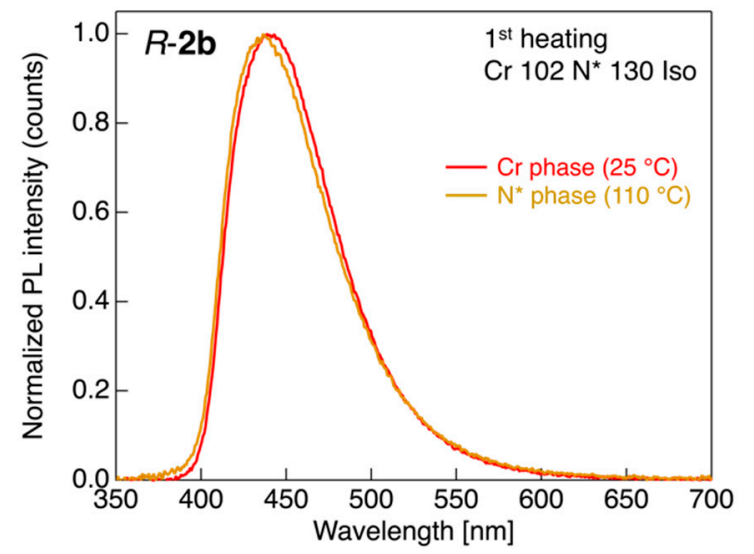

(c)

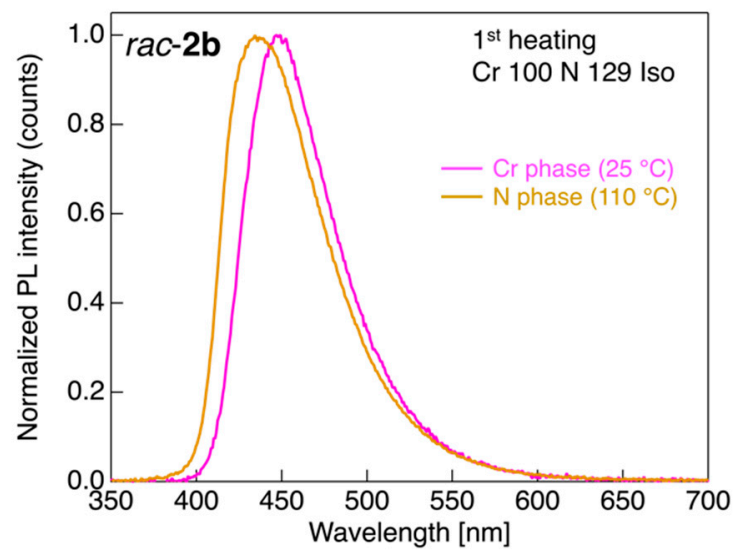

(b)

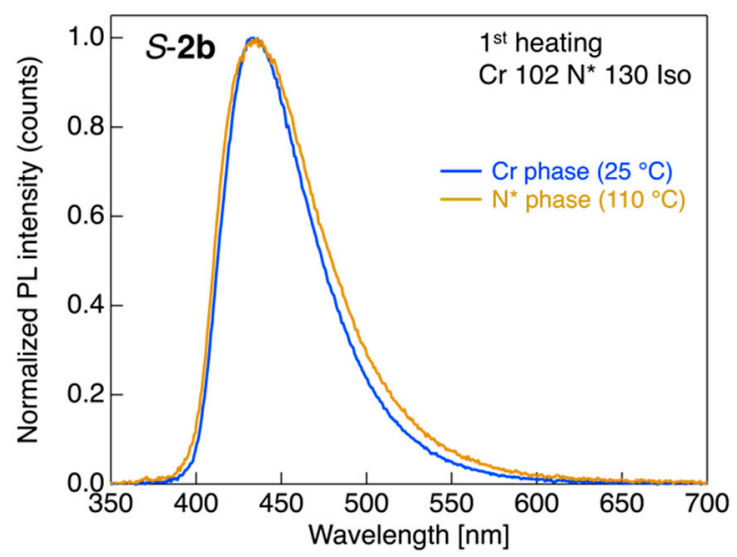

(d)

Figure 7. PL spectra of (a) 2a with Cr-phase (green) and N-phase (yellow) molecular aggregates, (b) rac-2b with Cr-phase (pink) and N-phase (yellow) molecular aggregates, (c) $R$-2 $\mathbf{b}$ with $\mathrm{Cr}$-phase (red) and $\mathrm{N}^{*}$-phase (yellow) molecular aggregates, and (d) $S$-2 b with Cr-phase (blue) and $\mathrm{N}^{*}$-phase (yellow) molecular aggregates. Abbreviations: $\mathrm{Cr}$ : crystal, $\mathrm{N}$ : nematic, $\mathrm{N}^{*}$ : chiral nematic, Iso: isotropic phases.

For 2a, the LC powder sample prepared as described above after the transition to the N-phase upon the first heating to $160{ }^{\circ} \mathrm{C}$ exhibited deep blue PL with a single band at around $442 \mathrm{~nm}$ and a shoulder peak at around $412 \mathrm{~nm}$. Compared to that of the as-prepared Cr sample, the above PL band was blue-shifted, slightly broadened, and less intense, probably because of the promotion of 
non-radiative deactivation through thermal molecular motions in the latter case. Similarly, the LC powder samples of rac-2b with N-phase molecular aggregates also emitted deep blue PL with a blue-shift of $\lambda_{\mathrm{PL}}$ by $15 \mathrm{~nm}$. Although the LC powder of $R-\mathbf{2} \mathbf{b}$ and $S-\mathbf{2} \mathbf{b}$ successfully showed deep blue PL with a single band at around $435 \mathrm{~nm}$ even in the $\mathrm{N}^{*}$-phase molecular aggregates, it was observed almost similar PL spectra to those of the as-prepared Cr sample. Thus, $\mathbf{2} \mathbf{a}, r a c-\mathbf{2} \mathbf{b}, R-\mathbf{2} \mathbf{b}$, and $S-\mathbf{2} \mathbf{b}$ exhibited PL not only in the Cr-phase but also in the LC phase after the thermal phase transition. In addition, a slight shift of PL band position with a similar tendency to our previous report [25] was observed after the formation of other molecular aggregates through the thermal phase transition, although the effect of the $\mathrm{Cr} \rightleftarrows \mathrm{LC}$ phase transition on PL behavior was not fully clear.

\section{Conclusions}

Pentafluorinated bistolanes with two types of flexible units (linear 2-methoxyethoxy and branched 1-methoxyprop-2-oxy) were prepared from readily accessible the corresponding 4-substituted phenylacetylene derivatives using a facile four-step procedure and subjected to phase transition and photophysical behavior evaluation. All of the synthesized bistolanes formed an LC phase upon both heating and cooling, and the temperature of this phase transition significantly decreased (compared to that of a simple butoxy-substituted derivative) upon the incorporation of oxygen and the introduction of a methyl substituent. For the chiral species, a fingerprint optical texture was observed in the mesophase, which clearly indicated the formation of a chiral nematic phase with helical molecular aggregates. Consequently, suitable modifications of flexible unit structure were found to affect the emergence of the LC phase and the phase transition temperature. UV-vis absorption measurements revealed that the four bistolanes exhibited identical electronic structures, and deep blue PL emission was observed in all cases in dilute solution. The species with a 1-methoxyprop-2-oxy chain showed solvatochromic PL (originating from radiative deactivation through ICT), i.e., the PL band shifted to the longer wavelengths with increasing solvent polarity. The present bistolanes showed significant PL ( $\Phi_{\mathrm{PL}}$ of up to 0.74 ) even in the crystalline phase, in which case the methyl substituent was believed to enhance $\Phi_{\mathrm{PL}}$ by promoting the expansion of interfacial $\pi \cdots \pi$ distances to avoid tight $\pi / \pi$ stacking. In addition, LC powders with preserved molecular aggregates in the LC phase also exhibited PL, which clearly indicated that the synthesized bistolanes are promising components of light-emitting liquid crystals and, hence, of next-generation functional materials.

Supplementary Materials: The following are available online at http://www.mdpi.com/2073-4352/10/7/603/s1, Figures S1-S14: ${ }^{1} \mathrm{H},{ }^{13} \mathrm{C}$, and ${ }^{19} \mathrm{~F}$ NMR spectra, Figures S15-S17: Optimized geometry, HOMO and LUMO distribution of 1, 2a, and S-2b, Figures S18-S21: DSC thermogram and POM images in the LC phase, Figure S22: Absorption and photoluminescence (PL) spectra, Figure S23: PL spectra of S-2b in various solvent, Figure S24: Lippert-Mataga plot, Figure S25: Excitation and PL spectra in crystalline phase, Figure S26: Excitation and PL spectra in the LC phase, Tables S1-S6: Cartesian coordinates for optimized geometries, Tables S7-S10: Phase transition behavior determined by DSC, Table S11: Polarizability and Stokes' shifts.

Author Contributions: Conceptualization, S.Y.; methodology, S.Y.; validation, S.Y., M.S., and T.K.; investigation, S.Y., M.S. and T.K.; writing-original draft preparation, S.Y.; writing-review and editing, S.Y., M.S., and T.K.; visualization, S.Y., M.S., and T.K.; supervision, S.Y.; project administration, S.Y.; funding acquisition, S.Y. All authors have read and agreed to the published version of the manuscript.

Funding: This research was funded by JSPS KAKENHI through a Grant-in-Aid for Scientific Research (C) (Grant No. JP18K05262).

Conflicts of Interest: The authors declare no conflict of interest.

\section{References}

1. Singh, H.; Tiwari, K.; Tiwari, R.; Pramanik, S.K.; Das, A. Small molecules as fluorescent probes for monitoring intracellular enzymatic transformations. Chem. Rev. 2019, 119, 11718-11760. [CrossRef] [PubMed]

2. Gu, X.; Kwok, R.T.K.; Lam, J.W.Y.; Tang, B.Z. AIEgens for biological process for monitoring and disease theranostics. Biomaterials 2017, 146, 115-135. [CrossRef] [PubMed] 
3. Hemmer, E.; Acosta-Mora, P.; Méndez-Ramos, J.; Fischer, S. Optical nanoprobes for biomedical applications: Shining a light on upconverting and near-infrared emitting nanoparticles for imaging, thermal sensing, and photodynamic therapy. J. Mater. Chem. B 2017, 5, 4365-4392. [CrossRef] [PubMed]

4. Chen, X.; Wang, F.; Hyun, J.Y.; Wei, T.; Qiang, J.; Ren, X.; Shin, I.; Yoon, J. Recent progress in the development of fluorescent, luminescent and colorimetric probes for detection of reactive oxygen and nitrogen species. Chem. Soc. Rev. 2016, 45, 2976-3016. [CrossRef]

5. Yang, Y.; Zhao, Q.; Feng, W.; Li, F. Luminescent chemodosimeters for bioimaging. Chem. Rev. 2013, 113, 192-270. [CrossRef]

6. Yersin, H. (Ed.) Highly Efficient OLEDs: Materials Based on Thermally Activated Delayed Fluorescence; Wiley-VCH: Weinheim, Germany, 2018.

7. Bui, T.-T.; Goubard, F.; Ibrahim-Ouali, M.; Gigmes, D.; Dumur, F. Recent advances on organic blue thermally activated delayed fluorescence (TADF) emitters for organic light-emitting diodes (OLEDs). Beilstein J. Org. Chem. 2018, 14, 282-308. [CrossRef]

8. Jhulki, S.; Moorthy, J.N. Small molecular hole-transporting materials (HTMs) in organic light-emitting diodes (OLEDs): Structural diversity and classification. J. Mater. Chem. C 2018, 6, 8280-8325. [CrossRef]

9. Gaspar, D.J.; Polikarpov, E. (Eds.) OLED Fundamentals: Materials, Devices, and Processing of Organic Light-Emitting Diodes; CRC Press: Boca Raton, FL, USA, 2015.

10. Ostroverkhova, O. Organic optoelectronic materials: Mechanisms and applications. Chem. Rev. 2016, 116, 13279-13412. [CrossRef]

11. Birks, J.B. (Ed.) Photophysics of Aromatic Molecules; Wiley: London, UK, 1970.

12. Thomas, S.W.; Joly, G.D.; Swager, T.M. Chemical sensors based on amplifying fluorescent conjugated polymers. Chem. Rev. 2007, 107, 1339-1386. [CrossRef]

13. Li, H.; Li, B.S.; Tang, B.Z. Molecular design, circularly polarized luminescence, and helical self-assembly of chiral aggregation-induced emission molecules. Chem. Asian J. 2019, 14, 674-688. [CrossRef]

14. He, Z.; Ke, C.; Tang, B.Z. Journey of aggregation-induced emission research. ACS Omega 2018, 3, 3267-3277. [CrossRef] [PubMed]

15. Mei, J.; Leung, N.L.C.; Kwok, R.T.K.; Lam, J.W.Y.; Tang, B.Z. Aggregation-induced emission: Together we shine, united we soar! Chem. Rev. 2015, 21, 11718-11940. [CrossRef] [PubMed]

16. Zhao, Z.; He, B.; Tang, B.Z. Aggregation-induces emission of siloles. Chem. Sci. 2015, 6, 5347-5365. [CrossRef] [PubMed]

17. Kumon, T.; Hashishita, S.; Kida, T.; Yamada, S.; Ishihara, T.; Konno, T. Gram-scale preparation of negative-type liquid crystals with a $\mathrm{CF}_{2} \mathrm{CF}_{2}$-carbocycle unit via an improved short-step synthetic protocol. Beilstein J. Org. Chem. 2018, 14, 148-154. [CrossRef]

18. Yamada, S.; Tamamoto, K.; Kida, T.; Asai, T.; Ishihara, T.; Konno, T. Rational design and synthesis of a novel laterally-tetrafluorinated tricyclic mesogen with large negative dielectric anisotropy. Org. Biomol. Chem. 2017, 15, 9442-9454. [CrossRef]

19. Yamada, S.; Hashishita, S.; Asai, T.; Ishiahra, T.; Konno, T. Design, synthesis and evaluation of new fluorinated liquid crystals bearing $\mathrm{CF}_{2} \mathrm{CF}_{2}$ fragment with negative dielectric anisotropy. Org. Biomol. Chem. 2017, 15, 1495-1509. [CrossRef]

20. Morita, M.; Yamada, S.; Konno, T. Fluorine-induced emission enhancement of tolanes via formation of tight molecular aggregates. New J. Chem. 2020, 44, 6704-6708. [CrossRef]

21. Yamada, S.; Nishizawa, A.; Morita, M.; Hosokai, T.; Okabayashi, Y.; Agou, T.; Hosoya, T.; Kubota, T.; Konno, T. Synthesis and characterization of bent fluorine-containing donor- $\pi$-acceptor molecules as intense luminophores with large Stokes shifts. Org. Biomol. Chem. 2019, 17, 6911-6919. [CrossRef]

22. Yamada, S.; Morita, M.; Konno, T. Multi-color photoluminescence induced by electron-density distribution of fluorinated bistolane derivatives. J. Fluor. Chem. 2017, 202, 54-64. [CrossRef]

23. Yamada, S.; Mitsuda, A.; Adachi, K.; Hara, M.; Konno, T. Development of light-emitting liquid-crystalline polymers with a pentafluorinated bistolane-based luminophore. New J. Chem. 2020, 44, 5684-5691. [CrossRef]

24. Morita, M.; Yamada, S.; Agou, T.; Kubota, T.; Konno, T. Luminescence tuning of fluorinated bistolanes via electronic or aggregated-structure control. Appl. Sci. 2019, 9, 1905. [CrossRef]

25. Yamada, S.; Miyano, K.; Agou, T.; Kubota, T.; Konno, T. 2-Chloroalkoxy-substituted pentafluorinated bistolanes as novel light-emitting liquid crystals. Crystals 2019, 9, 195. [CrossRef] 
26. Yamada, S.; Miyano, K.; Konno, T.; Agou, T.; Kubota, T.; Hosokai, T. Fluorine-containing bistolanes as light-emitting liquid crystalline molecules. Org. Biomol. Chem. 2017, 15, 5949-5958. [CrossRef] [PubMed]

27. Frisch, M.J.; Trucks, G.W.; Schlegel, H.B.; Scuseria, G.E.; Robb, M.A.; Cheeseman, J.R.; Scalmani, G.; Barone, V.; Petersson, G.A.; Nakatsuji, H.; et al. Gaussian 16, Revision B.01; Gaussian, Inc.: Wallingford, CT, USA, 2016.

28. Zhao, Y.; Truhlar, D.G. The M06 suite of density functionals for main group thermochemistry, thermochemical kinetics, noncovalent interactions, excited states, and transition elements: Two new functionals and systematic testing of four M06-class functionals and 12 other functionals. Theor. Chem. Acc. 2008, 120, 215-241.

29. Chan, B.; Gilbert, A.T.B.; Gill, P.M.W.; Radom, L. Performance of density functional theory procedures for the calculation of proton-exchange barriers: Unusual behavior of M06-type functionals. J. Chem. Theory Comput. 2014, 10, 3777-3783. [CrossRef] [PubMed]

30. Andzelm, J.; Kölmel, C.; Klamt, A. Incorporation of solvent effects into density functional calculations of molecular energies and geometries. J. Chem. Phys. 1995, 103, 9312-9320. [CrossRef]

31. Barone, V.; Cossi, M. Quantum calculation of molecular energies and energy gradients in solution by a conductor solvent model. J. Phys. Chem. A 1998, 102, 1995-2001. [CrossRef]

32. Cossi, M.; Rega, N.; Scalmani, G.; Barone, V. Energies, structures, and electronic properties of molecules in solution with the C-PCM solvation model. J. Comput. Chem. 2003, 24, 669-681. [CrossRef]

33. Tamura, R.; Takahashi, H.; Ushio, T. New enantiomeric resolution phenomenon of racemic crystals: Preferential enrichment. J. Synth. Org. Chem. Jpn. 1998, 56, 22-33. [CrossRef]

34. Gelebart, A.H.; Mulder, D.J.; Varga, M.; Konya, A.; Ghislaine, V.; Meijer, E.W.; Selinger, R.L.B.; Broer, D.J. Making waves in a photoactive polymer film. Nature 2017, 546, 632-636. [CrossRef]

35. Ravi, M.; Samanta, A.; Radhakrishnan, T. Excited state dipole moments from an efficient analysis of solvatochromic Stokes shift data. J. Phys. Chem. 1994, 98, 9133-9136. [CrossRef]

36. Yao, H.; Okada, T.; Mataga, N. Solvation-induced charge separation in the excited state of composite systems with identical halves and intramolecular excimer formation by recombination: Picosecond laser photolysis studies on 1,2-dianthrylethanes. J. Phys. Chem. 1989, 93, 7388-7394. [CrossRef]

37. Mataga, N.; Kaifu, Y.; Koizumi, M. The solvent effect on fluorescence spectrum. Change of solute-solvent interaction during the lifetime of excited solute molecule. Bull. Chem. Soc. Jpn. 1955, 28, 690-691. [CrossRef]

38. Iida, A.; Yamaguchi, S. Intense solid-state blue emission with a small Stokes' shift: $\pi$-Stacking protection of the diphenylanthracene skeleton. Chem. Commun. 2009, 3002-3004. [CrossRef] 